\title{
Thoughts on Education and Teaching of Students Major in Music of Local Free Normal University and Colleges in Ethnic Minority Areas
}

\author{
Ying Jiang \\ Sichuan Minzu College, \\ Kangding, Sichuan, 626001 \\ E-mail: 358173205@qq.com
}

\begin{abstract}
In order to address the shortage of teaching staff in ethnic minorities in western China, western provinces, after the releasing of the tuition-free policy for the normal university undergraduates, have recruited government-funded normal university students. The policy aims to cultivate qualified primary and secondary school teachers for ethnic minority regions, but the outcome is not desirous. This paper takes the free normal university students major in music in ethnic minority regions as the research object, adopts interview, investigation and analysis to shed light on the student source of ethnic minority normal students at public expense, find the reason behind and offer countermeasures, in a bid to provide reference for education and teaching of ethnic minority free normal university students major in music.
\end{abstract}

Keywords - music major; ethnic minority free normal university students; student source; education and teaching thinking

Implemented in 2007, the tuition-free policy for the normal university undergraduates initially was available to sixes normal universities directly under the Ministry of Education. Financially supported by the Central Government, free normal students do not have to pay for the tuition or the accommodation, and they even enjoy living allowances. Normal universities of varied provinces and municipalities have followed the suit to enroll the free normal students called local free normal students whose relevant expenditure are undertaken by the local government. However, these students are required to go back to where they come to teach in primary and secondary schools. With the deepening of the policy, more and more ethnic minority students apply for local normal university for free education. This paper reflects and researches on the situation and education of local normal university students majoring in music.

I. THE STUDENT SOURCE CONDITION OF THE LOCAL NORMAL UNIVERSITY AT THE PUBLIC EXPENSE OF ETHNIC MINORITIES

The author teaches in a university for nationalities located in the region inhabited by ethnic groups. In 2017, it enrolled the first batch of local free normal students who are mainly from ethnic minority areas and remote mountain area. Compared with peers from prosperous regions, these students

This paper is the phased achievement of The First Batch of First-Class Undergraduate Professional Construction Sites in Sichuan University for Nationalities. File No. CMYF [2019]68 have the following characteristics.

\section{A. Narrow horizon and little experience}

They are generally ignorant with a narrow horizon. For example, they may not know the things that are common to students from cities. The only approach for them to know the world is the TV. Ethnic minority normal university students admitted in said that they found out how narrow they were after entering big cities for intensive college entrance examination training through various means. They have not seen or heard of the piano. They know nothing about staff, even basic music knowledge. Their music lessons in the previous school are either not offered, or led by the teacher to dance and sing folk songs. Most schools do not have full-time music teachers. Almost all teachers and students to learn music only to sing and dance step by step. While recruiting students in local ethnic minority areas, parents are confused about the necessity to learn music and dance. They hold that if one can speak then he can sing, if talk and can dance.

\section{B. Too stereotyped to accept new things}

The current domestic music education system is established by referring to western music education system. It requires students to learn piano, vocal music, solfeggio and music theories. However, these students influenced by their living conditions, local customs and sense of style, are hard to accept the current education system, and even reluctant to learn piano, vocal music and theories. All that they are interested in is their own folk dance and music.

\section{Lack of motivation, good learning habits, and learning strategies}

Some students lack enthusiasm for learning, resulting in academic procrastination. They have no learning plan or time arrangement. The situation can be attributed to the lack of competition for jobs and the unreasonable assessment system. Firstly, the admission of public normal university students is bound with the employment agreement, that is to say, the public normal university students can get a secure job after graduation. Secondly, the assessment method is a combination of teaching and testing. The test papers will be designed and graded by the course teacher. In most cases, the course teacher will help underline the key points before theoretical tests and 
score based on human relationship in skill test. Given this, students can get a graduation certificate with ease. In a word, without employment pressure, evaluation issues or the desire to realize self-worth, students naturally have no motivation for learning. [1]

There are still some students who have a strong willingness to learn, but without effective learning approaches. For, example, they can hardly adapt to the teaching model in school as they have been accustomed to the oral imparting with physical instruction. Moreover, they are unable to learn independently and rely much on students, only to be infused while knowing nothing about the things that have not been taught by teachers. They are not able to acquire knowledge from multiple channels or make use of resources available (such as network, library, etc.) for extended learning.

\section{Weak professional foundation}

With the preferential policy of national college entrance examination for ethnic minority students, the admission line of ethnic minority local normal university students is much lower than that of ordinary normal university students. Many ethnic minority normal university students admitted have a very weak professional foundation. They are not proficient in staff, original ecological singing of vocal music, piano, or solfeggio and have no theoretical knowledge. Therefore, it is a challenge for educators to train them to be qualified music teachers in primary and secondary schools within four years.

\section{THINKING ON EDUCATION AND TEACHING OF MiNORITY NORMAL UNIVERSITY STUDENTS AT PUBLIC EXPENSE}

\section{A. Broaden the horizon, open the mind, improve the thought, and change the old idea}

As the saying goes, notion determines the direction and how you think determines how far you go. Therefore, to change one's destiny, it is necessary to improve his notion. To change the notions of these free normal students, it is essential to broaden their horizon and enrich their spirit. However, the normal universities in the minority regions are located where there are insulated from the outside world. How to strengthen the contact between the students and the outside world, so that they can perceive the richness and development of the world, better change their minds and improve themselves during the three or four years of study? This is an urgent question for all universities located in the minority regions. It should be realized that only working by schools themselves are far from enough, instead, that issue should be solved at the national level with the joint efforts of the society. At present, the Ministry of Education has held the activities to invite refined art to schools, which offers students the opportunities to know more about the world in certain degree. However, due to the limited number of such activities held each year, it is impossible to give them continuous and long-term edification, and the effect is very weak. Therefore, in addition to the educational infrastructure, the state should strengthen the construction of multi-culture in ethnic areas.

\section{B. Set courses reasonably}

Due to the particularity of these students, curriculum should be set accordingly and reasonably. However, most universities still adhere to the curriculum system designed for ordinary normal students, which raises the difficulty of learning for minority normal university students. The current curriculum of normal university students mainly consists of general courses, professional basic courses, professional development courses and education and teaching courses. In view of the future teaching career, it is necessary to increase the class hours and credits of basic professional courses and reduce those of the professional development courses which are more profound and complicated for ethnic minority normal university students with poor foundation.[2]

In addition, the teaching of music professional courses in normal universities is quite different from that of music courses in primary and secondary schools in terms of teaching tasks, plans, processes and goals. Due to the lack of music courses in primary and secondary schools, minority normal university students have no idea about how to teach music courses in the schools. A Tibetan normal university student at public expense said that their previous music class is to sing folk songs, dance Guozhuang with the teacher, which is not the real music class. Once standing in front of the students, they feel very confused. Therefore, it is necessary to strengthen the professional education courses of minority normal university students at public expense. Firstly, practical teaching should run through the whole process of normal university students' cultivation. For example, practical teaching can be arranged since the sophomore year, and students should regularly enter the classroom of primary and secondary schools to learn about the specific situation of primary and secondary school students and the current situation of education and teaching. In the third and fourth years, practical teaching should be strengthened step by step. The one-time educational practice can be divided into several sections, so that students can understand their own problems through the practice and fill in the gaps. Secondly, it is necessary to combine theory with practice by strengthening the combination of professional practice courses and educational theory courses. Thirdly, in practice guidance and management, teachers of primary and secondary schools should make joint efforts. For example, Professional Development Schools in the United States and Partnership Schools in the United Kingdom are communities composed of university teachers and primary and secondary school teachers to jointly undertake the internship guidance of normal university students.[3] Fourthly, excellent music teachers can be invited to deliver lectures, conduct demonstration teaching, impart teaching experience, promote the new national curriculum and the national education policy, etc., so as to let the ethnic minority students get to know the basic music education status and the demand, and improve and enrich themselves in a timely manner, in order to adapt to the future basic music teaching.[4] In addition, for minority normal university students at public expense, music classes in primary and secondary schools in minority areas with good development are worth further study. These schools generally attach importance to integrating local music art into classroom teaching, so that children can receive basic music education and inherit their own national music art. 


\section{Cultivate students' good study habits and guide them to broaden access to knowledge}

Francis Bacon, British philosopher, wrote in The Essays that habit is a strong and great power that can dominate life. Ye Shengtao, contemporary Chinese educator said that education is just cultivating the habit. A good habit is the foundation and guarantee of success. For many reasons, minority normal university students generally lack good study habits, but the habit cannot be formed overnight. Therefore, it is necessary to help students develop a good habit from the freshman year. As college students are mature in mind, universities need to strengthen communication with them and have a deep understanding of them, so as to influence them from various aspects, such as example demonstration and self-confidence training, so as to help them gradually establish good habits.

The ancients said, it's better to teach a man to fish than to give him a fish. That is to say, the ways to acquire knowledge is more important that the knowledge itself. At present, the students acquire knowledge path mainly comes from the teacher's lectures, but interactive teaching is needed. The more advanced teaching methods emphasize much more on autonomous learning. Therefore, teachers should change their minds and get off high horse to establish the new relationship with students. They need to help create a relaxed and free learning environment, treat students equally with mutual learning attitude, guide students to make full use of resources (library, Internet, etc.), through reading, listening, study, observation and practice to obtain knowledge and skills.

\section{Appropriately introduce ethnic and folk-art teaching to increase students' interest in learning}

Different nationalities with varied natural environments, life styles and customs give birth to music arts with their own characteristics. However, at present, even in normal colleges and universities in ethnic minority areas, music major's teaching system is all in western mode, with highly westernized courses and relatively difficult courses, which greatly discourages ethnic minority normal students' learning enthusiasm.

How to add ethnic music elements in music professional courses for free normal university students, to let ethnic art and western teaching system complement and promote each other is a subject that we need to study and discuss which is of great practical significance. It is viable to introduce some national music art to the professional course. For example, excellent national songs can be inserted in the teaching of bel canto. The piano music adapted from folk songs and Guozhuang solfeggio can be added in the piano teaching. Research collaboration can be conducted with ethnic minority students, for instance, discussion on the similarities and differences of original singing and bel canto (folk singing), and exploration on how to enrich ethnic music by the western harmony system and so on, through which students can learn comparatively, and feel the music arts of different regions, different cultures, so as to eliminated the exclusion of western music system while deepening understanding of their own national art, in a bid to improve their learning interest.

\section{E. Improve the exit mechanism to put pressure on free normal university students}

Tuition-free policy for the normal university undergraduates from ethnic minorities is designed to offer a opportunity for students who are willing to take over the primary and secondary school education in their hometowns. Having addressed the students' employment issue, it also produces lazy students without the sense of responsibility, or sense of mission. Therefore, this policy also needs to be optimized reasonably. It can implement the mechanism to allow students to be admitted easily but graduate strictly. For those who fail to graduate on time, it is necessary to claim for breach of contract for they cannot fulfill the teaching agreement.[5] In addition, evaluation system of colleges and universities can be reformed with rich the assessment forms. Separating testing from teaching can evaluate the students strictly, fairly and impartially, so as to strictly control the production. This can effectively curb teachers' perfunctory teaching, students' undisciplined study and other unhealthy phenomena, to ensure the cultivation of qualified primary and secondary school music teachers.[6]

\section{CONCLUSION}

Education is the foundation of the centenary plan. In recent years, the state has increased its investment in education, especially the basic education in ethnic minority areas and remote mountainous areas. Music education in for public funded normal university students in ethnic minority areas has met great difficulties, but at the same time enjoyed huge development potential. It should find a way of development with ethnic characteristics. How to better integrate the music art of ethnic minorities into the daily teaching of music major in normal universities, to enable Chinese and western music complement each other, is an important reform topic that teachers in normal universities in the ethnic areas need to actively practice and explore.

\section{REFERENCES}

[1] Wang Xinguo. Analysis and Countermeasures of Academic Failure of Tuition-Free Normal University Students - Taking H Major of D University as an Example [D] Changchun, Northeast Normal University.2013:3-7

[2] Yang Jie. On the Training Mode of Free Normal Students in Music Colleges and Universities [J]The World of Music, 2012(9):40-42

[3] Liu Zixia. On the Training Mode of Free Normal University Students and the Effects[D]Shanghai, East China Normal University, 2012:77

[4] Chen Fang. On the Adaptation of Tuition-Free Normal University Students to Basic Music Education [D] Chongqin, Southwest University, 2014: 76

[5] Zhang Lei. On the Motivation of Free Normal University Students Major in Musicology [D]Xi'an, Shaanxi Normal University, 2017:31

[6] Long Wenxiang. Reflection on the Rationality of "The Specification of Teaching from Testing” System in Colleges and Universities[J]. Journal of Inner Mongolia Normal University, 2009(2): 81-86. 